\title{
Tobacco packaging and labelling policies in countries of the Eastern Mediterranean and Western Pacific Regions: Post-deadline assessment of the time-bound measures of WHO FCTC Article 11
}

\author{
Aya Mostafa' ${ }^{1}$, Mina Kashiwabara
}

\begin{abstract}
InTRoduction Article 11 of the World Health Organization Framework Convention on Tobacco Control (WHO FCTC) forms the basis for regulation of tobacco product packaging and labelling. Countries are required to implement these measures within three years after becoming a Party to the Convention. This paper aims to assess the progress made in the implementation of Article 11 in countries of the Eastern Mediterranean Region (EMR) and Western Pacific Region (WPR) in relation to the entry into force of the WHO FCTC, highlighting regional differences.

METHODS We assessed the tobacco control laws and regulations up to December 2014 from all 49 countries in both regions against 15 time-bound measures of Article 11.

RESULTS Most countries (44, 90\%) adopted text-based health warnings. After they were formally bound by the Convention, 25 countries (51\%) introduced pictorial health warnings (PHWs); 13 (59\%) in the EMR and $12(44 \%)$ in the WPR. However, only 11 countries (44\%) met the deadline. Overall, just 10 countries $(20 \%)$ were highly compliant with the time-bound measures, yet none was fully compliant with all 15 measures. The most common adopted time-bound measure was mandating health warnings in the national tobacco control laws (90\%), while the least common was banning descriptors depicting flavours (4\%).

concLusıons Ratifying the WHO FCTC created a breakthrough in implementing some time-bound measures of Article 11 and strengthening health warnings, specifically facilitating the introduction of PHWs in both regions. Continued efforts to fully implement the time-bound measures of Article 11 are still needed in both regions.
\end{abstract}

\section{AFFILIATION}

1 Department of Community, Environmental, and Occupationa Medicine, Faculty of Medicine Ain Shams University, Cairo, Egypt

2 World Health Organization, Regional Office for the Western Pacific, Manila, Philippines

CORRESPONDENCE TO

Dr. Aya Mostafa Department of Community, Environmental and Occupational Medicine, Faculty of Medicine, Ain Shams University, Cairo, Egypt, 38 Ramses street, Abbassia Square, 11566 Cairo, Egypt. Email: aya. kamaleldin@med.asu.edu.eg

\section{KEYWORDS}

Packaging and labelling, health warnings, WHO FCTC, tobacco control legislations, Eastern Mediterranean Region, Western Pacific Region

\section{INTRODUCTION}

Well-designed health warnings on tobacco product packages are a cost-effective means to encourage cessation and discourage initiation of tobacco use $\mathrm{e}^{1-15}$. Pictorial health warnings (PHWs) are particularly useful in communicating health effects to the poor, less educated, children and youth ${ }^{1-15}$. Public health legislation that requires effective tobacco product packaging and labelling is a key component of an integrated approach to tobacco control and is recommended as one of the key demand reduction measures by the World Health Organization (WHO) Framework Convention on Tobacco Control (FCTC) ${ }^{16}$.

The WHO FCTC was adopted in 2003 in response to the global epidemic of tobacco, and entered into force on 27
February 2005 in those countries that were already Parties at that time ${ }^{17}$. Countries became Parties to the Convention at different times even after its entry into force. Each Party has an obligation to implement all the required provisions of the Convention $^{17}{ }^{18}$. Since its introduction, the WHO FCTC has served as a guide for countries in developing effective and comprehensive tobacco control laws to protect the public from the dangers of tobacco ${ }^{17-19}$. Article 11 of the Convention provides best practice characteristics of packaging and labelling of tobacco products, including time-bound measures, which all Parties are required to implement within three years after entry into force of the treaty for that Party (Table 1) ${ }^{17-19}$.

Despite the international obligation, many countries, 
especially low- and middle-income countries with high tobacco use, still have ineffective or no health warnings on tobacco products $^{16,20}$. Globally, only 42 countries have implemented large PHWs, among which, only four are low-income countries (Bangladesh*, Madagascar, Nepal and Niger) ${ }^{16}$. This paper focuses on two of the six WHO regions, the Eastern Mediterranean Region (EMR) and the Western Pacific Region (WPR), which are similar in terms of the distribution of countries across income levels; in each region, one-fourth are high-income countries, two-thirds are middle-income, and the rest are low-income ${ }^{21,22}$. Both regions suffer from high rates of adult daily smoking-almost half of the countries have prevalence rates exceeding $20 \%$ and as high as $31 \%$ in Jordan and $46 \%$ in Kiribati ${ }^{23}$.

More than ten years have passed since the WHO FCTC became effective, and the deadlines for implementation of the time-bound measures of Article 11 have passed for all Parties in the EMR and the WPR (Table 2) ${ }^{17-19,24,25}$. The 2014 Global Progress Report on implementation of the WHO FCTC summarized whether countries had implemented Article 11, comparing the past two reporting cycles in 2012 and $2014^{26}$. In addition to focusing on a limited time range, this report lacked some important details. First, it did not report the dates when countries first implemented the time-bound measures. Second, the information was on overall progress by all Parties to the Convention and thus did not allow comparisons by country or region. Third, the report was based on Parties' self-reports, which may be in favour of reporting positive progress-there might have been conflation between the stated text in the country's tobacco control law and actual implementation. These factors are crucial to evaluating whether ratifying the Convention has brought about significant progress in addressing Article 11 requirements in tobacco control laws. There is also scarce research on cross-regional comparisons of the implementation of the time-bound measures of the Convention ${ }^{27}$.

The objective of this study is to assess the progress made in tobacco packaging and labelling policies by countries in the EMR and the WPR before and after they were formally bound by the WHO FCTC. We also aim to identify gaps between existing tobacco control laws and the time-bound measures of Article 11, and key differences between the two regions.

\section{METHODS}

\section{Collection of tobacco control laws in EMR and WPR countries}

We collected laws, including legislation, regulations, decrees, bylaws and circulars addressing tobacco packaging and labelling-adopted before 31 December 2014-from the 49 countries in the EMR $(n=22)$ and the WPR $(n=27)$ (Table 2).
These laws were provided by health ministries and obtained through Internet searches ${ }^{28}$.

Adoption of the WHO FCTC by EMR and WPR countries Each country was specifically examined for (a) whether and when it became a Party to the WHO FCTC, and if so, (b) when the WHO FCTC entered into force in the country ${ }^{24,25}$. We then identified (c) the deadline for each country to meet the time-bound requirements of Article 11, particularly under its first clause (Article 11.1). All WPR countries were Parties to the WHO FCTC; in the EMR, Morocco, Palestine*, and Somalia were non-Parties until December 2014, the end of the study period (Table 2).

Terminology related to the adoption of the WHO FCTC were defined as per Articles 34, 35 and 36 of the Convention ${ }^{29}$ : a) Party to the WHO FCTC: The WHO FCTC was adopted by the World Health Assembly on 21 May 2003 and entered into force on 27 February $2005^{29}$. The Convention was open for signature by all Members of WHO or the United Nations until 29 June $2004^{24}$. During this period, all members in both regions signed the WHO FCTC, except for Bahrain, Oman, Palestine*, Somalia, and Nauru. After June 2004, a country became a Party to the WHO FCTC following the deposit of its instrument of ratification, acceptance, or accession ${ }^{24}$. By December 2014, 46 countries in both the EMR and the WPR had become Parties to Convention.

b) Entry into force: The WHO FCTC entered into force on the ninetieth day following the date by which the Party ratified, accepted, or acceded to it ${ }^{29}$. For countries that have become Parties to the Convention before November 2004, the Convention became effective on 27 February 2007.

c) Deadlines for Article 11 implementation of the timebound measures: Article 11 requires certain measures to be adopted and implemented at country level within a period of three years after the entry into force of the Convention ${ }^{29}$. Accordingly, deadlines were calculated for each of the Parties.

\section{Extraction of time-bound measures from Article 11.1 of the WHO FCTC}

We reviewed the text of Article 11.1 in light of its implementation guidelines ${ }^{17-19}$, and identified 15 time-bound measures (Table 1).

\section{Assessment of the progress in tobacco packaging and labelling policies in EMR and WPR countries}

We initially examined the progress of each country with regards to their tobacco control laws and their status with respect to the WHO FCTC. Countries were examined specifically for whether and when: (a) the country adopted a tobacco control 
law, (b) the law addressed tobacco packaging and labelling policies, and if so, (c) did these policies mandate health warnings on all tobacco products, and (d) were these health warnings textual, pictorial, or both.

After reviewing the specifications of the health warnings required in the existing laws, we assessed whether the laws fulfilled the 15 time-bound measures. We assigned 1 point to each measure, so that a tobacco control law in full compliance with these measures scored 15 out of 15 . According to their compliance scores, the countries were further grouped into three categories: high $(\geq 75 \%)$, moderate $(50 \%$ to $<75 \%)$ and low compliance $(<50 \%)$.

\section{RESULTS}

By December 2014, the vast majority of the 49 EMR and WPR countries $(44,90 \%)$ had national tobacco control laws requiring some form of health warnings $(20,91 \%$ in the EMR and $24,89 \%$ in the WPR). Text-based health warnings were introduced in 26 countries before and in 18 countries after adoption of the WHO FCTC in 2003. Pictorial health warnings (PHWs) were introduced in 25 Parties (51\%; 13 EMR and 12 WPR countries). Adopting the WHO FCTC resulted in a statistically significant increase in the number of countries implementing PHWs, which were used in only two countries before, versus 23 countries (93\%) after, entry into force of the Convention (Figure 1).

Many countries adopted basic text warnings within or even before the implementation deadline (36 countries, $86 \%$ ). However, only 11 (44\%) succeeded in introducing PHWs before the three-year period; this was achieved by more EMR (64\%) than WPR countries (46\%) (Figure 1). Singapore was the first country to introduce PHWs in 2003, the same year that the WHO FCTC was adopted by the World Health Assembly. In the following year, Jordan was the first country in the EMR to adopt PHWs. No health warnings have been introduced in Afghanistan*, Federated States of Micronesia (FSM), Niue and Palau — despite being Parties to the WHO FCTC—and in Somalia, which was a non-Party until December 2014, the end of the study period (Figure 1).

Some countries introduced health warnings on tobacco products long before adoption of the WHO FCTC. Pakistan (1979), Egypt (1981) and Sudan (1983) were amongst the first countries in the EMR to apply text-based health warnings on tobacco products. In the WPR, there was a surge of health warning legislation in the early to mid-1970s; small, mandatory text warnings were introduced in Australia (1973), Japan (1972), Malaysia (1976), New Zealand (1974) and the

Table 1. Time bound Measures of the WHOFCTC Article 11.1*

WHOFCTC Article 11.1

Each Party shall, within a period of three years after entry into force of this Convention for that Party, adopt and implement, in accordance with its national law, effective measures toensure that:

WHIO FCTC Article II.I text
merresponding time bound
assessment for

a. tobacco product packaging and labelling do not promote a tobacco product by any means that are false, misleading, deceptive or likely to create an erroneous impression about its characteristics, health effects, hazards or emissions, including any term, descriptor, trademark, figurative or any other sign that directly or indirectly creates the false impression that a particular tobacco product is less harmful than other tobacco products. These may include terms such as "low tar", "light", "ultra-light", or "mild"; and

b. each unit packet and package of tobacco products and any outside packaging and labelling of such products also carry health warnings describing the harmful effects of tobacco use, and may include other appropriate messages. These warnings and messages:

i. shall be approved by the competent national authority,

ii. shall be rotating,
iii. shall be large, clear, visible and legible,

iv. should be $50 \%$ or more of the principal display areas but shall be no less than $30 \%$ of the principal display areas,

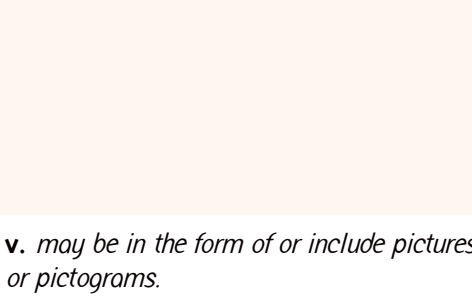

*Details of each provision were identified from the implementation guidelines of Article 11.
1. Misleading terms banned

2. Figurative signs banned

3. Descriptors depicting flavours banned

4. Health warnings present on each unit and outside packaging 5. Health warnings describe harmful effects of tobacco use

6. Health warnings mandated by national laws

7. Law mandates specific health warnings

8. Health warnings rotate

9. Health warnings placed on both front and back principal display areas

10. Health warnings placed at the top of principal display areas 11. Opening of the package does not conceal health warnings

12. Health warning occupies $50 \%$ or more of principal display areas 13. Health warning occupies no less than $30 \%$ of principal display areas

14. Text of the health warnings in specific font, size, style and colour

15. Health warning include pictures/pictograms 
Table 2. Countries included in this study, by WHO Regions

Eastern Vediterranean Region $\quad$ IVestern Pacific Region
(EVIR)

$\begin{array}{ll}\text { 1. Afghanistan } & \text { 1. Australia } \\ \text { 2. Bahrain } & \text { 2. Brunei Darussalam } \\ \text { 3. Djibouti } & \text { 3. Cambodia } \\ \text { 4. Egypt } & \text { 4. China } \\ \text { 5. Iraq } & \text { 5. Cook Islands } \\ \text { 6. Islamic Republic of Iran (Iran) } & \text { 6. Federated States of Micronesia } \\ \text { 7. Jordan } & \text { (FSM) } \\ \text { 8. Kuwait } & \text { 7. Fiji } \\ \text { 9. Lebanon } & \text { 8. Japan } \\ \text { 10. Libya } & \text { 9. Kiribati } \\ \text { 11. Morocco* } & \text { 10. Lao People's Democratic } \\ \text { 12. Oman } & \text { Republic (Lao PDR) } \\ \text { 13. Pakistan } & \text { 11. Malaysia } \\ \text { 14. Palestine** } & \text { 12. Marshall Islands } \\ \text { 15. Qatar } & \text { 13. Mongolia } \\ \text { 16. Saudi Arabia } & \text { 14. Nauru } \\ \text { 17. Somalia* } & \text { 15. New Zealand } \\ \text { 18. Sudan } & \text { 16. Niue } \\ \text { 19. Syrian Arab Republic (Syria) } & \text { 17. Palau } \\ \text { 20. Tunisia } & \text { 18. Papua New Guinea } \\ \text { 21. United Arab Emirates (UAE) } & \text { 19. Philippines } \\ \text { 22. Yemen } & \text { 20. Republic of Korea } \\ & \text { 21. Samoa } \\ & \text { 22. Singapore } \\ & \text { 23. Solomon Islands } \\ & \text { 24. Tonga } \\ & \text { 25. Tuvalu } \\ \text { 26. Vanuatu } \\ \text { 27. Viet Nam }\end{array}$

*Not Parties to WHO FCTC.

${ }^{* *}$ Not a WHO Member State.
Republic of Korea (1976). Most countries started with small text-only health warnings, and then adopted PHWs after ratifying the WHO FCTC (Figures 1 and 2).

The number of countries mandating some form of health warnings has tripled in the past three decades. By 1995, 15 countries had required text-based health warnings. By 2003, about half of the EMR and WPR countries had done so (26 countries: 15 in the WPR, 11 in the EMR). After the entry into force of the WHO FCTC, there was a spike in the introduction of health warnings in both regions. More recently, in 2012 in the EMR and 2013 in the WPR, there was a surge in implementing PHWs (Figure 2).

Provisions on health warnings were not always applicable to all types of tobacco products. In six countries, tobacco control legislation health warnings were not required on certain types of tobacco products. In Jordan, Pakistan, Cambodia and Malaysia, the existing laws mandated health warnings on cigarettes only but not on other forms of tobacco. In Kiribati, nimoko-a type of smoked tobacco produced locally-are exempted from health warnings.

The size of health warnings on cigarette packs were stipulated in the tobacco control laws of 39 out of 44 countries (89\%) that required health warnings by December 2014 (Figure 3). Tobacco control laws in the Marshall Islands, Morocco, Papua New Guinea, Syria and Tunisia did not

Figure 1. Implementation of health warnings by country in relation to the WHOFCTC required timelines*

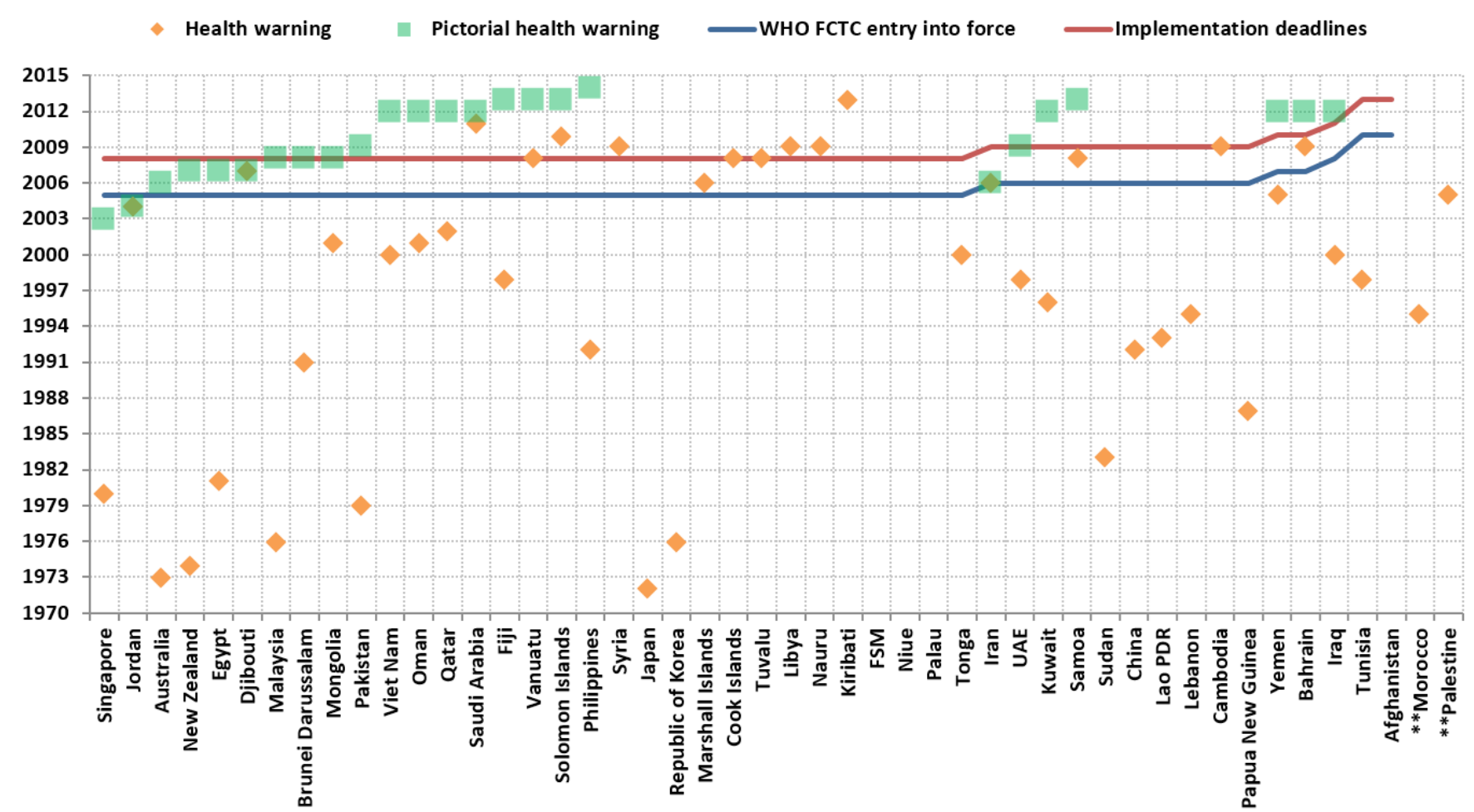

* Countries sorted by Party/non to the WHO FCTC, then by date of entry into force to the WHO FCTC, then by date of introduction of PHW.

** Morocco and Palestine are not Parties to the WHO FCTC, but have adopted health warnings. Somalia is not included in Figure 1 , as it is not Party to the WHO FCTC and did not adopt health warnings. 
Figure 2. Number of countries that implemented tobacco control laws in requiring textual health warnings pictorial health warnings by region, 1970-2014*

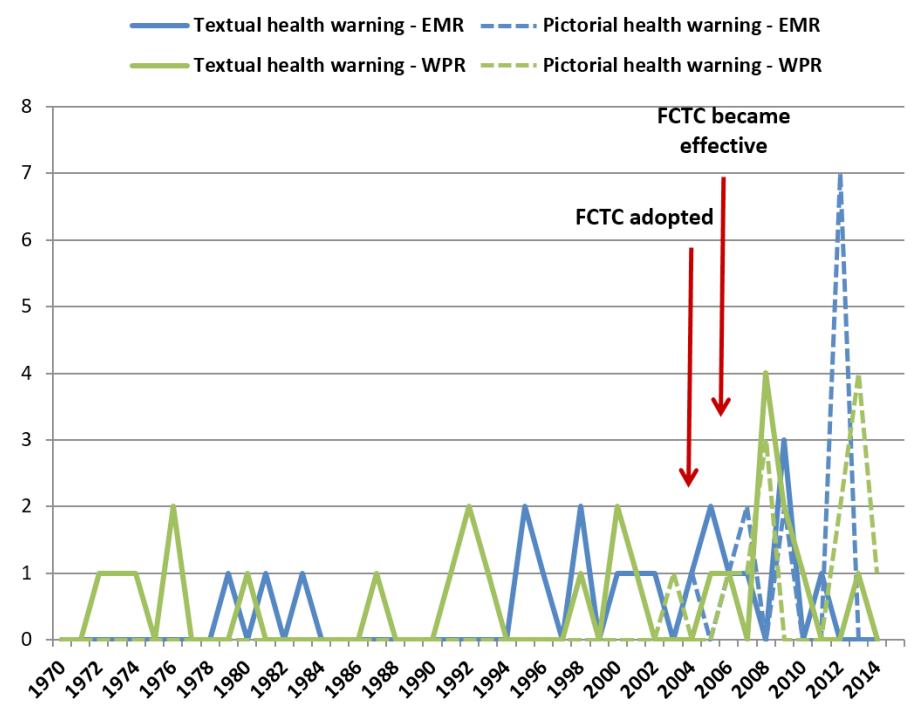

*Countries that introduced textual and pictorial warnings in the same year are counted into both categories for that year.

specify the percentage of the main display areas that health warnings must occupy on tobacco packs. The largest health warnings covering $83 \%$ of the principal display areas $(75 \%$ of front and $90 \%$ of back) were used in Australia and Brunei Darussalam (75\% of both front and back). Pakistan issued new regulations in 2015 requiring picture and text warnings to be placed on $85 \%$ of the front and back of all cigarette packs; however, implementation of these requirements has been delayed. Countries specified the size of health warnings either by providing specific percentages on the front or the rear of tobacco packs or combined, with the exception of four Parties (Libya, Nauru, Palestine and Sudan) that required warnings on the front only.

The number of EMR and WPR countries that implemented each of the 15 time-bound measures under Article 11.1 by December 2014 is shown in Figure 4. In both regions, thirty six countries (74\%) mandated health warnings larger than $30 \%$ of the principal display areas-the minimum size required by the WHO FCTC. However, the recommended size of $50 \%$ or more was achieved in only 23 countries (47\%) (Figure 4). Provisions on size varied depending on the type of tobacco product, and in some cases smaller health warnings were mandated on other tobacco products compared to those required on cigarettes. For instance, Fiji required health warnings on other smoked tobacco products to cover $33 \%$ of the display area, almost half of what is required for cigarettes packs.

Specific health warnings were mandated by tobacco control laws in most countries (78\%) (Figure 4), while Iraq, Kiribati,
Figure 3. Percentage of the principal display areas covered by the health warnings*

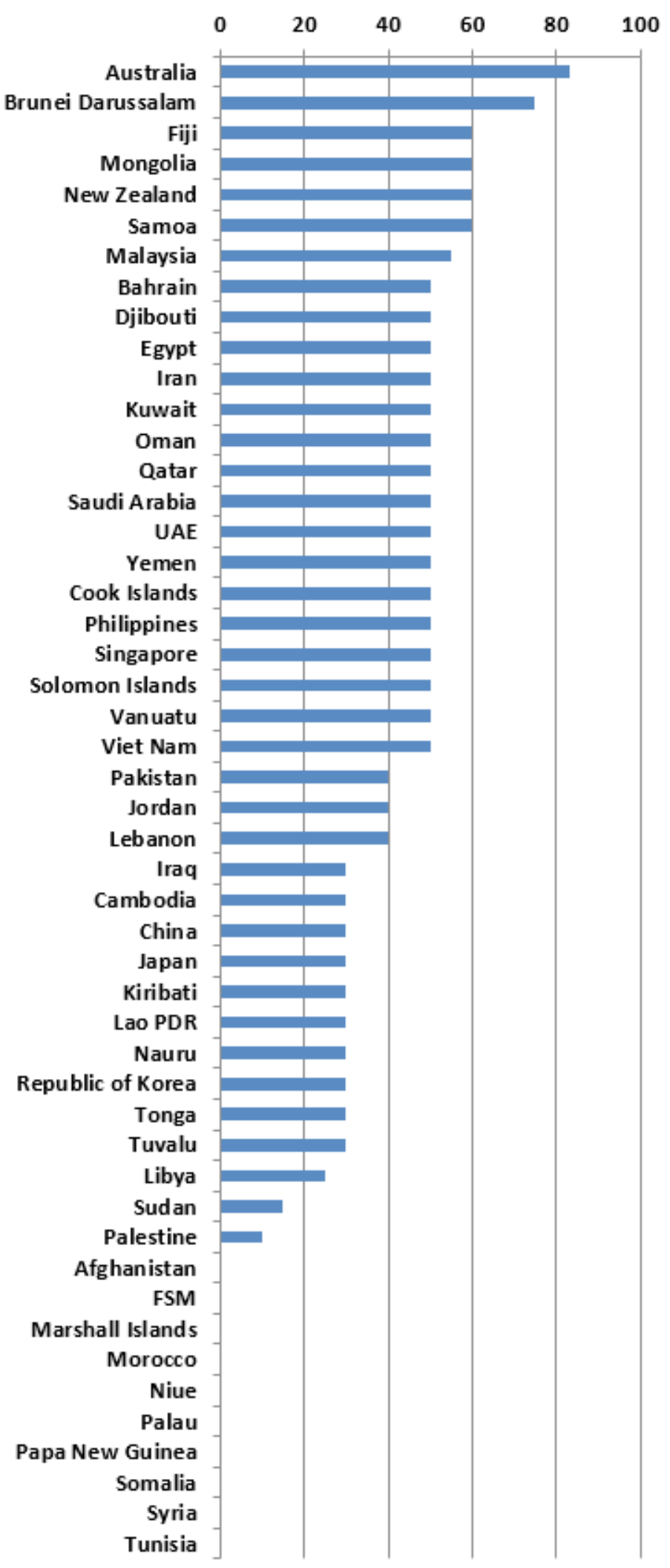

* Principal display areas are the two largest surfaces (usually front and back of a typical tobacco pack) of a tobacco package. Data by December 2014. 
Marshall Islands, Papua New Guinea, Tonga and Tuvalu did not specify what warning message should be placed. Australia, New Zealand and Samoa had the widest approved variety of health warnings (14), followed by Iran (13) Lebanon, Malaysia, and Philippines (12), Djibouti (11), and Solomon Islands (10). Eight countries had only one approved health warning.

Approximately $90 \%$ of countries in both regions required that health warnings be mandated by national tobacco control laws, representing the most adopted time-bound measure, followed by other measures requiring descriptions of the harmful effects of tobacco use, and that health warnings rotate $(78 \%)$ (Figure 4). The least adopted measures in both regions were banning of figurative signs (14\%) and descriptors on flavours (4\%), both of which are related to misleading labelling and packaging features.

Most time-bound measures were implemented at similar percentages in both regions. However, a large gap between the two regions was found for some measures. More WPR versus EMR countries required that health warnings be displayed on each unit and outside packaging ( $81 \%$ versus $50 \%$ ), and that warnings be placed at the top of display areas ( $48 \%$ versus $14 \%)$. Conversely, more EMR versus WPR countries required

Figure 4. Healt h warning provisions required by the country's tobacco control laws compared to the time bound measures of Article 11.1 of the WHOFCTC

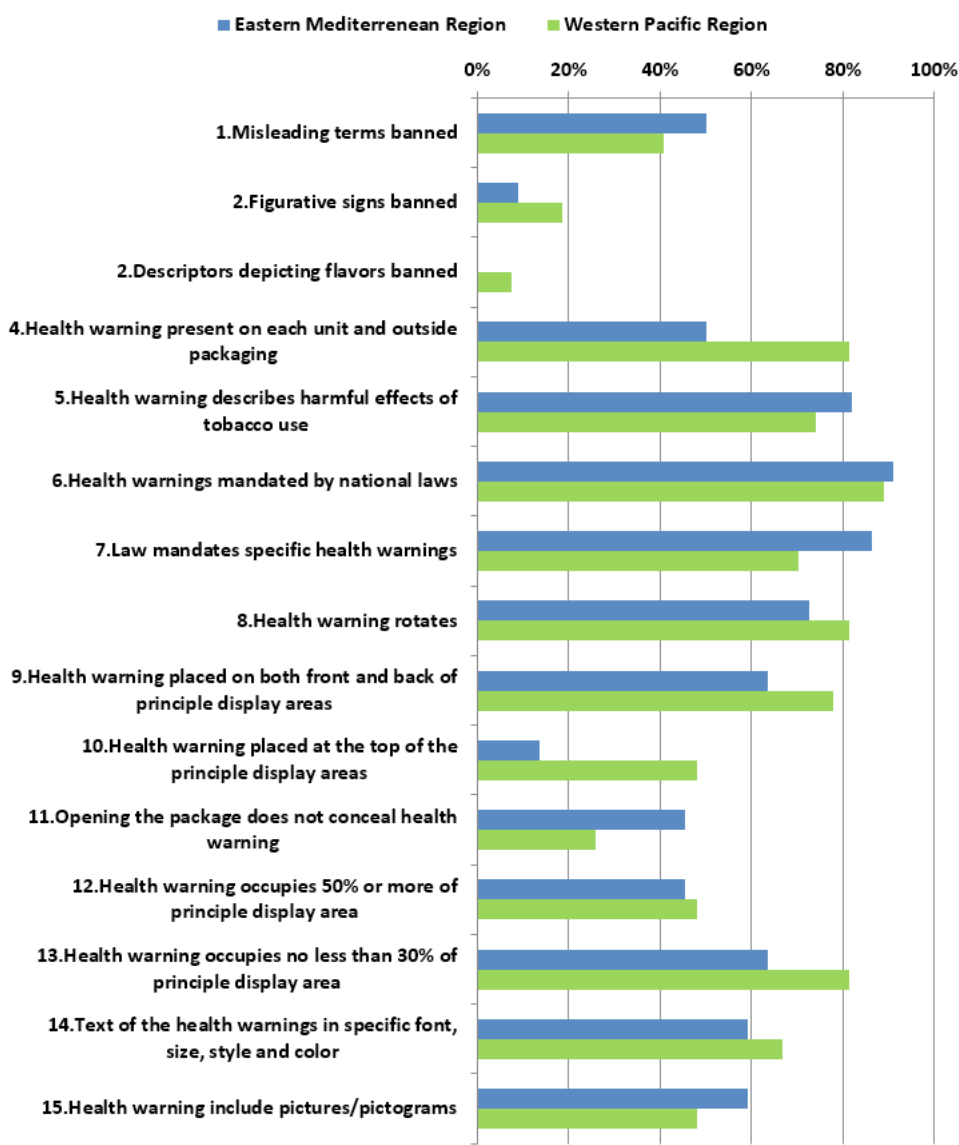

Figure 5. Compliance with tobacco control laws in EMR and WPR countries with the time bound measures of Article 11.1 of the WHOFCTC"
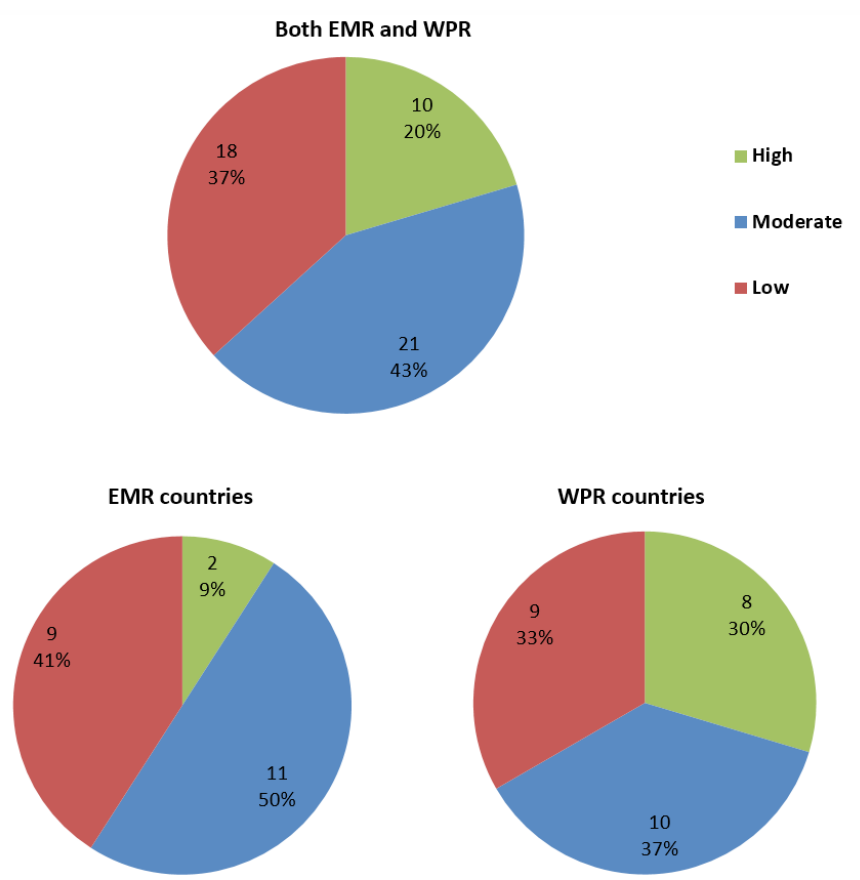

* Grouping of countries is according to time-bound requirements as described in Table 1.

that warnings not be concealed when opening the tobacco package ( $45 \%$ versus $26 \%$ ), and that they include pictures or pictograms (59\% versus 44\%) (Figure 4).

The majority of countries implemented more than half of the time-bound requirements of Article 11.1. In both regions, 10 countries $(20 \%)$ achieved the highest level of compliance (Figure 5). None of the countries was fully compliant with all 15 time-bound measures. The most compliant were Djibouti (93\%) and Iran (80\%) from the EMR, and Australia, Singapore (93\%), Malaysia, Solomon Islands (87\%), Cook Islands, Mongolia, Samoa and the Philippines (80\%) from the WPR. Twenty-one countries (43\%) achieved moderate compliance. Overall, more WPR countries have complied with more time-bound measures than EMR countries.

\section{DISCUSSION}

This study demonstrates that ratifying the WHO FCTC created a breakthrough in the implementation of some time-bound measures of Article 11, specifically, accelerating the introduction of PHWs. In both the EMR and the WPR, PHWs were adopted by only two countries before, versus 23 countries (92\%) after, entry into force of the WHO FCTC. Only 11 countries (44\%) succeeded in meeting the deadline for PHW implementation, and no country was fully compliant with all 15 time-bound measures. However, they still served 
as a guide for countries to develop more comprehensive measures in relation to health warnings. After entry into force of the Convention, most countries took at least some action to be more compliant with Article 11 requirements, such as increasing the size of health warnings.

Before adoption of the Convention, a decade after the United States Surgeon General's Report on Smoking and Health was published $(1964)^{30}$, text-based health warnings were already in place as early as the 1970s-80s in some countries. However, there were large variations in their progress towards addressing the requirements of Article 11 in tobacco control legislation.

For instance, in the EMR, text-based health warnings on tobacco packs were first required in both Egypt and Sudan circa 1980s. Yet, after the entry into force of the WHO FCTC, Egypt succeeded in introducing PHWs before the implementation deadline, while Sudan still required text-based health warnings only ${ }^{28}$. Conversely, Djibouti did not have any earlier forms of health warnings, but succeeded in introducing both text-based and PHWs simultaneously for the first time after ratifying the WHO FCTC ${ }^{28}$. Moreover, it was the most compliant country (93\%) in the EMR with Article 11 time-bound measures. This example highlights the significance of ratifying the Convention and countries' possible subsequent achievements when tobacco industry interferences are minimized.

Similarly, in the WPR, Japan was amongst the first countries in the world to adopt text-based health warnings, but due to tobacco industry interference, did not yet adopt $\mathrm{PHWs}^{31}$. On the other hand, Australia legislated health warnings in the early 1970s and introduced PHWs soon after ratifying the Convention. Furthermore, Australia became the pioneer in introducing plain packaging, going beyond the time-bound measures of Article $11^{15}$. Plain packaging includes restricting the use of logos, colours, brand images or promotional information on packaging other than brand and product names in standard colour and font ${ }^{32}$.

Australia has succeeded in challenging the tobacco industry in becoming the first country to fully implement plain packaging in 2012, which contributed to a significant decline in the country's smoking prevalence ${ }^{33}$, 34. There is evidence that insertion of large $\mathrm{PHWs}$ on tobacco packs averts tobacco-attributable deaths. Globally, seven countries, including Egypt from the EMR and Malaysia from the WPR, averted 1.4 million tobaccorelated deaths between 2007 and 2010 by adopting large PHWs alone ${ }^{33}$, 35. The positive impact of implementing PHWs would be tremendous, considering that $52 \%$ of the countries adopting large PHWs in both regions implemented this measure recently between 2012 and
2014 (Figure 2). The reduction in smoking prevalence attributable to plain packaging may indicate that a packaging policy alone could result in many more lives saved.

Despite this advancement, there are still many challenges for countries in both regions. Overall, only 10 countries (20\%) were compliant with more than $75 \%$ of the required time-bound provisions on health warnings. The majority of countries still need to develop or strengthen their tobacco control legislation and mandate effective PHWs that are in line with all 15 timebound measures of Article 11 of the WHO FCTC, as well as to extend these measures to include all tobacco products. Some countries such as Afghanistan, Cambodia, Pakistan, Lao People's Democratic Republic, Republic of Korea and Vanuatu have introduced stronger health warning laws after our review period, thus data presented in this paper do not reflect the latest status in those countries.

Not all 15 time-bound measures were addressed equally by the countries' tobacco control legislation. The most common adopted measure was health warnings mandated by national tobacco control laws (90\%), followed by health warning requirements to describe harmful effects of tobacco use, to rotate and to state specific health warnings (78\%). Some measures were more common in WPR countries than in EMR countries, and vice versa. Such differences should be further studied to identify barriers and enablers in implementing particular measures.

Notably, misleading tobacco labelling and packaging remained the least adopted time-bound measure in both regions, especially the banning of figurative signs and (14\%) descriptors depicting flavours (4\%). The tobacco industry exploited some loopholes in tobacco control laws and used figurative signs and flavours as their single remaining powerful tactic to attract as many potential smokers as possible, in countries where many of the timebound measures were already in place.

Other common loopholes identified included a narrow umbrella under the definition of tobacco products. The definition usually covered tobacco products commonly found in the localities. Yet some countries mandated stronger warning labels on manufactured cigarettes than on other tobacco forms, and some did not require any warning labels for other types of tobacco. This was especially problematic in countries with high rates of other tobacco product use, and may have led people to believe that products without PHWs were less harmful ${ }^{16,36}$.

Smokeless tobacco products and other forms of smoked tobacco (hand-rolled cigarettes, bidis, kreteks, cigars, cigarillos, pipe tobacco) are used in both regions $s^{37-45}$. For example, waterpipe tobacco was traditionally used across countries of 
the EMR and in few countries in the WPR, but it has recently surpassed cigarette use in some countries ${ }^{37-45}$. In Malaysia, one in three female tobacco users consumed smokeless tobacco alone, but PHWs were required by law on cigarettes only ${ }^{20}$. Furthermore, new forms of tobacco are constantly being invented, exploiting loopholes in existing tobacco control laws. This creates an additional challenge to countries already struggling to contain the growing tobacco epidemic ${ }^{37-43}$. Therefore, health warning provisions must cover all types of tobacco products equally, and should consider specific health effects related to each ${ }^{1,}$ ${ }^{17-19}$ Nonetheless, the tobacco industry interference has hampered some countries' efforts to fully implement the time-bound measures. Countries must remain vigilant against legal challenges by the industry. For instance, single-stick sales should be regulated in many middle- and low-income countries because these reduce tobacco users' exposure to health warnings on cigarette packs ${ }^{46}$. All countries should continuously evaluate their tobacco control legislation to ensure its comprehensiveness, and closely and constantly monitor the tobacco industry's attempts to undermine existing health warning laws. Also, adopting tobacco control legislation per se seems unlikely to be sufficient, and countries should rather adopt a multisectoral policy to ensure the overall success of their combined tobacco control measures.

Countries that have achieved high compliance with the time-bound measures need to continuously monitor and evaluate the impact of enforcement of PHWs on demand and consumption. Evidence generated from this process would in turn help other countries to pursue higher levels of compliance with Article 11 requirements. These countries should consider adopting plain packaging to strengthen the effectiveness of their PHWs, as recommended by the implementation guidelines of Articles 11 and 13 of the WHO FCTC ${ }^{32}$. There is evidence that PHWs are more salient when introduced on plain packaging ${ }^{47-50}$. Some studies have also related plain packaging with increased urgency among smokers to quit, and with increased quit attempts ${ }^{51,52}$.

Countries with moderate compliance are recommended to conduct a detailed analysis of their tobacco control legislation to identify all possible gaps. Improving the existing laws may be particularly challenging when they are not under the jurisdiction of health ministries. For instance, in the member countries of the Cooperation Council for the Arab States of the Gulf (GCC), the GCC Specification Authority is responsible for amending health warning regulations ${ }^{28}$. In Japan, health warning regulations fall under the responsibility of the Ministry of Finance, which owns one-third of the stocks of Japan Tobacco, Inc ${ }^{53}$.

Finally, in countries with low compliance or where health warnings are not yet legislated, there is an immediate need to adopt legislation that addresses all the requirements of Article 11. Health ministries should take the lead in this process and strengthen collaboration with local stakeholders, briefing both the media and other involved authorities. These countries should also give due importance to flexibility in tobacco control legislation, allowing room for future amendments when needed. For example, issuing ministerial decrees is one model that may allow the addition of possible required elements in the future, while at the same time overcoming the rigidity in national legislation controlling PHW specifications.

Countries should not permit any involvement from the tobacco industry in developing and enforcing the health warnings, as such compromises will negatively impact the targeted health outcomes. Therefore, each national partner involved in this process should sign a declaration of interest to ensure transparency and avoid any conflicts of interest. Article 5.3 of the WHO FCTC must be rigorously implemented to avoid tobacco industry interference.

\section{CONCLUSION}

In conclusion, signing of the WHO FCTC was a significant factor in implementing at least some of the time-bound measures of Article 11 in both EMR and WPR countries. Adoption of the Convention helped these countries to strengthen health warnings and facilitated the introduction of $\mathrm{PHWs}$ on tobacco packs. Although much has been accomplished, continued efforts are needed to support proper enforcement of the existing laws and to conduct evaluation and monitoring of the effectiveness of PHWs. Countries that have not yet implemented all the required health warning provisions of Article 11 are recommended to assess their existing laws to identify gaps and ways to strengthen them. Countries that lack PHWs must exert comprehensive efforts to adopt all the required provisions of Article 11 of the Convention. All countries should prevent tobacco industry interference at every step of this process.

\section{REFERENCES}

1. Hammond D: Tobacco labelling \& packaging toolkit: A guide to FCTC Article 11. Chapter 1 Evidence review 2009, 9-46. Available from: http://www.tobaccolabels.ca/wp/wp-content/uploads/2013/12/ IUATLD-Tookit-Complete-Mar-3-2009.pdf/ (accessed June 2016).

2. Villanti AC, Cantrell J, Pearson JL, Vallone DM, Rath JM: Perceptions and perceived impact of graphic cigarette health warning labels on smoking behavior among U.S. young adults. Nicotine Tob Res 2014, 16(4):469-477. DOI: 10.1093/ntr/ntt176.

3. Azagba S, Sharaf MF: The effect of graphic cigarette warning labels on smoking behavior: evidence from the Canadian experience. 
Nicotine Tob Res 2013, 15:708-717. DOI: 10.1093/ntr/nts194.

4. Vardavas CI, Connolly G, Karamanolis K, Kafatos A: Adolescents perceived effectiveness of the proposed European graphic tobacco warning labels. Eur J Pub Health 2009, 19(2):212-217. DOI: 10.1093/eurpub/ckp015.

5. O'Hegarty M, Pederson LL, Nelson DE, Mowery P, Gable JM, Wortley P: Reactions of young adult smokers to warning labels on cigarette packages. Am J Prev Med 2006, 30:467-473. DOI: 10.1016/j.amepre.2006.01.018.

6. White V, Webster B, Wakefield M: Do graphic health warning labels have an impact on adolescents' smoking-related beliefs and behaviours? Addiction 2008, 103(9):1562-1571. DOI: 10.1111/j.1360-0443.2008.02294.x.

7. Borland R, Hill D: Initial impact of the new Australian tobacco health warnings on knowledge and beliefs. Tob Control 1997, 6:317-325. PMID: 9583630.

8. Hammond D, Fong GT, Borland R, Cummings KM, McNeill A, Driezen $P$ : Text and graphic warnings on cigarette packages: findings from the international tobacco control four country study. Am J Prev Med 2007, 32:202-209. DOI: 10.1016/j.amepre.2006.11.011.

9. Hammond D, Fong GT, McNeill A, Borland R, Cummings K M: Effectiveness of cigarette warning labels in informing smokers about the risks of smoking: findings from the International Control Four Country Study. Tob Control 2006, 15(III):19-25. DOI: 10.1136/ tc.2005.012294.

10. Cunningham R: Cigarette package warning size and use of pictures: international summary. Canadian Cancer Society 2011:13. Available from:.http://www.tobaccolabels.ca/wp/wp-content/ uploads/2014/04/Cigarette-Package-Warning-Size-and-Use-ofPictures-International-Summary-Cunningham-Feb-2014.pdf/ (accessed January 2015).

11. Institute for Global Tobacco Control. State of Evidence Review: Health Warning Labels on tobacco products 2013. Available from: http://www.globaltobaccocontrol.org/sites/default/files/ HealthWarnings_state_of_evidence_final_11_18_2013_web_0. pdf/ (accessed December 2014).

12. Centers for Disease Control and Prevention. Cigarette Package Health Warnings and Interest in Quitting Smoking -14 Countries, 2008-2010. MMWR Morb Mortal Wkly Rep 2011, 60(20):645651. Available from: http://www.cdc.gov/mmwr/pdf/wk/mm6020. pdf/ (accessed January 2015).

13. European Commission. Eurobarometer: Survey on tobacco (analytical report) 2009. Available from: http://ec.europa.eu/ public_opinion/flash/fl_253_en.pdf/(accessed June 2016).

14. Centers for Disease Control and Prevention. Health Warnings on Tobacco Products - Worldwide, 2007. MMWR Morb Mortal Wkly Rep 2009, 58(19):528-529. Available from: http://www.cdc.gov/ mmwr/PDF/wk/mm5819.pdf/ (accessed January 2015).

15. Shanahan P, Elliott D: Evaluation of the effectiveness of the graphic health warnings of tobacco product packaging 2008. Australian Government Department of Health and Ageing, Canberra 2009. Available from: http://www.smoke-free.ca/warnings/ WarningsResearch/australia/hw-eval-full-report.pdf/ (accessed June 2016).

16. World Health Organization. WHO report on the global tobacco epidemic, 2011. Warning about the dangers of tobacco. Available from: http://www.who.int/tobacco/global_report/2011/en/index. $\mathrm{html} /$ (accessed December 2014).

17. World Health Organization. WHO Framework Convention on Tobacco Control 2003. Available from: http://www.who.int/ tobacco/framework/en/ (accessed February 2014).

18. World Health Organization. Guidelines for implementation of Article 11 of the WHO Framework Convention on Tobacco Control (packaging and labelling of tobacco products) 2008. Available from: http://www.who.int/fctc/guidelines/article_11.pdf/ (accessed February 2014).

19. World Health Organization. Framework Convention on Tobacco Control. Elaboration of guidelines for implementation of Article 11 of the Convention 2008. Available from: http://apps.who.int/gb/ fctc/PDF/cop3/FCTC_COP3_7-en.pdf/ (accessed February 2014).

20. World Health Organization. Tobacco Free Initiative. Global Adult Tobacco Survey 2015. Available from: http://www.who.int/tobacco/ surveillance/gats/en/ (accessed January 2015).

21. World Bank. Data. Country and Lending Groups. Available from: http://data.worldbank.org/about/country-and-lending-groups/ (accessed June 2016)

22. World Bank. Data. New Country Classifications. Available from: http://data.worldbank.org/news/new-country-classifications-2015/ (accessed June 2016)

23. World Health Organization. WHO report on the global tobacco epidemic, 2015. Raising Taxes on Tobacco. Available from: http:// apps.who.int/iris/bitstream/10665/178574/1/9789240694606_ eng.pdf?ua=1\&ua=1/ (accessed October 2016)

24. World Health Organization. Parties to the WHO Framework Convention on Tobacco Control. Available from: http://www.who. int/fctc/signatories_parties/en/ (accessed June 2016)

25. United Nations. Treaty Collection. Chapter IX Health. 4. WHO Framework Convention on Tobacco Control. Available from: https:// treaties.un.org/pages/ViewDetails.aspx?src=TREATY\&mtdsg_ no $=I X-4 \&$ chapter $=9 \&$ clang=_en/ (accessed June 2016).

26. World Health Organization. 2014 global progress report on implementation of the WHO Framework Convention on Tobacco Control. Available from: http://www.who.int/fctc/reporting/2014g lobalprogressreport.pdf/ (accessed June 2016).

27. Awopegba AJ, Cohen JE: Country tobacco laws and article 11 of the WHO Framework Convention on Tobacco Control: a review of tobacco packaging and labeling regulations of 25 countries. Tob Induc Dis 2013, 11:23. DOI: 10.1186/1617-9625-11-23.

28. World Health Organization. Regional Office for the Eastern Mediterranean Region. Tobacco Free Initiative. Country Legislation. Available from: http://www.emro.who.int/tobacco/legislation/ country-legislation.html/ (accessed January 2015).

29. World Health Organization. WHO Framework Convention on Tobacco Control. Available from: http://apps.who.int/iris/bitstre am/10665/42811/1/9241591013.pdf?ua=1/ (accessed October 2016)

30. U.S. Department of Health and Human Services. The Health Consequences of Smoking: 50 Years of Progress. A Report of the Surgeon General. Atlanta, GA: U.S. Department of Health and Human Services, Centers for Disease Control and Prevention, National Center for Chronic Disease Prevention and Health Promotion, Office on Smoking and Health, 2014. Printed with corrections, January 2014. Available from: http://www.surgeongeneral.gov/ library/reports/50-years-of-progress/full-report.pdf/ (accessed June 2016).

31. Satomura K, Iwanaga S, Noami M, Sakamoto R, Kusaka K, Nakahara T: The Framework Convention on Tobacco Control (FCTC) and Japanese anti-tobacco measures. Tob Induc Dis 2008, 31, 4:3. DOI: 10.1186/1617-9625-4-3.

32. World Health Organization. WHO global health days. World No Tobacco Day. Frequently asked questions: Plain packaging of tobacco products 31 May 2016. Available from: http://www.who. int/campaigns/no-tobacco-day/2016/faq-plain-packaging/en/. (accessed October 2016).

33. Levy DT, Ellis JA, Mays D, Huang AT: Smoking-related deaths averted due to three years of policy progress. Bull World Health Organ 2013, 91:509-518. DOI: 10.2471/BLT.12.113878.

34. Pascal A Diethelm, Timothy M Farley. Refuting tobacco-industry 
funded research: empirical data shows decline in smoking prevalence following introduction of plain packaging in Australia. Tob. Prev. Cessation 2015;1(November):6

doi: $10.18332 / \mathrm{tpc} / 60650$

35. Post-Implementation Review Tobacco Plain Packaging 2016. Australian Government. Department of Health. Available from: https://ris.govspace.gov.au/files/2016/02/Tobacco-PlainPackaging-PIR.pdf/ (accessed June 2016)

36. Roskin J, Avevard P: Canadian and English students' beliefs about waterpipe smoking: a qualitative study. BMC Public Health 2009, 10:9-10. DOI: 10.1186/1471-2458-9-10.

37. The Tobacco Atlas. Smokelss Tobacco. Available from: http://www. tobaccoatlas.org/topic/smokeless-tobacco/ (accessed June 2016).

38. Conner RJ: Non-cigarette tobacco products: what have we learnt and where are we headed? Tob Control 2012, 21:181-190. Available from:http://tobaccocontrol.bmj.com/content/21/2/181.full/ (accessed June 2016). DOI: 10.1136/tobaccocontrol-2011-050281.

39. Nakkash R, Khalil J: Health warning labelling practices on narghile (shisha, hookah) waterpipe tobacco products and related accessories. Tob Control 2010, 19:235-239. DOI: 10.1136/tc.2009.031773.

40. Centers for Disease Control and Prevention. Global Tobacco Surveillance System Data. Available from: http://nccd.cdc.gov/ gtssdata/Ancillary/DataReports.aspx?CAID=3/ (accessed June 2016)

41. World Health Organization. Tobacco Free Initiative. Global Youth Tobacco Survey 2015. Available from: http://www.who.int/tobacco/ surveillance/gats/en/ (accessed January 2015).

42. World Health Organization. WHO report on the global tobacco epidemic, 2015. Raising taxes on tobacco. Available from: http:// www.who.int/tobacco/global_report/2015/en/ (accessed June 2016).

43. World Health Organization. WHO Framework Convention on Tobacco Control Implementation Database. Available from: http:// apps.who.int/fctc/implementation/database/ (accessed June 2016).

44. Vupputuri S, Hajat C, Al-Houqani M, Osman O, Sreedharan J, Ali R, Crookes AE, Zhou S, Sherman SE, Weitzman M; United Arab Emirates Tobacco Control Research Collaborative: Midwakh/dokha tobacco use in the Middle East: much to learn. Tob Control 2016, 25:236-241. DOI: 10.1136/tobaccocontrol-2013-051530.

45. Maziak W, Ben Taleb Z, Bahelah R, Islam F, Jaber R, Auf R, Salloum RG: The global epidemiology of waterpipe smoking. Tob Control 2015, 24:i3-i12. DOI: 10.1136/tobaccocontrol-2014-051903.

46. Singh A, Owusu-Dabo E, Britton J: "Pictures don't lie, seeing is believing": exploring attitudes to the introduction of pictorial warnings on cigarette packs in Ghana. Nicotine Tob Res 2014, 16(12):1613-1619. DOI: 10.1093/ntr/ntu127.

47. Maynard OM, Munafo MR, Leonards U: Visual attention to health warnings on plain tobacco packaging in adolescent smokers and nonsmokers. Addiction 2013, 108(2):413-419. DOI: 10.1111/j.13600443.2012.04028.x.

48. Maynard OM, Leonards U, Attwood AS, Bauld L, Hogarth L, Munafo MR: Plain packaging of cigarettes and smoking behavior: study protocol for a randomized controlled study. Trials 2014, 15:252. DOI: $10.1186 / 1745-6215-15-252$

49. Hogarth L, Maynard OM, Munafo MR: Plain cigarette packs do not exert Pavlovian to instrumental transfer of control over tobacco-seeking. Addiction 2015, 110(1):174-182. DOI: 10.1111/ add. 12756.

50. Maynard OM, Leonards U, Attwood AS, Bauld L, Hogarth L, Munafo MR: Effects of first exposure to plain cigarette packaging on smoking behaviour and attitudes: a randomised controlled study. BMC Public Health 2015, 15:240. DOI: 10.1186/s12889-015-1586-8.

51. Wakefield MA, Hayes L, Durkin S, Borland R: Introduction effects of the Australian plain packaging policy on adult smokers: a crosssectional study. BMJ Open 2013, 3(7) pii: e003175. DOI: 10.1136/ bmjopen-2013-003175.

52. Durkin S, Brennan E, Coomber K, Zacher M, Scollo M, Wakefield M. Short-term changes in quitting-related cognitions and behaviours after the implementation of plain packaging with larger health warnings: findings from a national cohort study with Australian adult smokers. Tob Control 2015, 24:ii26-ii32. DOI: 10.1136/ tobaccocontrol-2014-052058.

53. Japan Tobacco Inc. - Company Profile, Information, Business Description, History, Background Information on Japan Tobacco Inc. Available from: http://www.referenceforbusiness.com/history2/70/ Japan-Tobacco-Inc.html/ (accessed June 2016).
ACKNOWLEDGEMENTS

We would like to express our sincere gratitude to Kerstin Schotte, Tobacco Free Initiative, World Health Organization, for her support throughout this work and her critical review of this article We would like to thank Tibor Szilagyi, and Lina Sovani, Convention Secretariat, WHO Framework Convention on Tobacco Control, for their insights and comments that greatly improved the manuscript. Special thanks to Fatimah El-Awa, Tobacco Free Initiative, World Health Organization, for her input into the discussion, and to Marine Perraudin, Tobacco Free Initiative, World Health Organization, for her technical assistance with the time-bound provisions of Article 11 of the WHO FCTC.

\section{CONFLICT OF INTEREST}

The authors have completed and submitted the ICMJE Form for Disclosure of Potential Conflicts of Interest and none were reported.

FUNDING

There was no source of funding for this research.

\section{PROVENANCE AND PEER} REVIEW

Not commissioned; externally peer reviewed. 